\title{
TIPS KETRAMPILAN MANAJEMEN UNTUK NAVIGASI DUNIA WIRAUSAHA
}

\author{
Aisya Amalia \\ Universitas Nahdlatul Ulama Sidoarjo \\ aisya@tutanota.com
}

Apakah dinding Anda dihiasi dengan gambar Richard Branson, Bill Gates atau Mark Zuckerberg?. Apakah Anda menemukan diri Anda terus-menerus bermimpi tentang menjalankan bisnis wirausaha kecil?. Apakah Anda suka mendiskusikan ide dan membuat sesuatu yang baru?. Maka tidak salah untuk mengatakan bahwa Anda ingin menjadi pengusaha dan memulai bisnis Anda sendiri suatu hari nanti. Untuk memenuhi impian itu di usia muda, penting untuk mengembangkan keterampilan wirausaha sejak dini. Berikut adalah beberapa tips untuk wirausahawan muda yang akan membantu dalam mengembangkan keterampilan wirausaha penting yang akan membantu Anda menavigasi melalui dunia bisnis. 


\section{Ingat Mengapa Anda Melakukan Semua Ini}

Dunia dan masyarakat membutuhkan kewirausahaan (Setyawati, Purnomo, Irawan, Tamyiz, \& Sutiksno, 2018). Pengusaha sukses menemukan motivasi dalam kenyataan bahwa mereka membuat keputusan sendiri dan mencapai visi yang benar-benar milik mereka. Ini adalah motivasi wirausaha terkuat dan paling efektif. Mereka secara langsung terkait dengan kesuksesan kewirausahaan. Terkadang, kehidupan sehari-hari dapat menjauhkan Anda dari alasan mendalam mengapa Anda melakukan petualangan kewirausahaan ini. Tetapi motivasi ini adalah bahan bakar Anda. Mereka memberi Anda energi untuk maju ketika masa sulit. Jadi luangkan waktu, sekali sehari, untuk berhenti. Cukup tanyakan pada diri sendiri: Mengapa saya melakukan semua ini? Apa yang mendorong saya? Apa yang memberi saya energi? Lihat, sesederhana itu (L'Écuyer, 2016).

\section{Memiliki Tim Hebat di Bawah Anda}

Jika Anda ingin membuat tangkapan terutama dalam bisnis dunia, Anda harus memiliki tim yang hebat yang akan bekerja sama untuk mengembangkan bisnis. Pilih individu yang sangat terampil yang dapat bekerja dengan Anda, dan pastikan mereka memiliki beragam talenta yang Anda butuhkan untuk sukses sebagai pengusaha. 
Setidaknya memiliki dua atau tiga orang di tim Anda yang memiliki pengalaman terbukti dan Anda adalah satu langkah menuju mencapai yang terbaik di dunia wirausaha (Kleim, 2018).

\section{Rekreasi Adalah Penciptaan Kembali}

Kita semua membuat kesalahan yang sama di tahun pertama. Kita semua dipompa dan siap menembakkan semua silinder. Kami makan dengan buruk. Kami jarang berolahraga. Dan kami merasa bersalah karena mengambil cuti sehari. Beristirahat tidak hanya baik untuk pikiran dan tubuh Anda, tetapi juga penting untuk bisnis Anda. Beberapa ide terbaik kami datang pada liburan atau tidak lama setelahnya, menghasilkan penciptaan nilai yang signifikan untuk Heyday. Sangat penting bahwa Anda mengambil satu langkah mundur sesekali: itu akan membantu Anda mendapatkan lebih banyak kejelasan tentang jalan ke depan dan memicu kreativitas baru (Mérineau, 2017).

\section{Gunakan Alat Yang Bermanfaat Untuk Membuat Konten}

Kesan pertama bisnis Anda terutama situs web memberi tahu lebih banyak tentang apa yang bisa diharapkan oleh pelanggan atau investor. Tidak ada yang lebih menyebalkan daripada menjelajah ke bidang yang Anda tidak tahu. Banyak pemula gagal 
karena pendiri mereka mendasarkan tindakan mereka pada gairah daripada penelitian dan data terperinci. Sebelum melakukan waktu, upaya, dan sumber daya Anda dalam bisnis, lakukan riset dan ketahui siapa target pelanggan Anda, apa yang sedang tren di pasar dan apa tantangannya. Ini akan membuat Anda diperbarui. Anda tidak ingin memulai dari awal lagi karena Anda gagal melakukan cukup banyak penelitian di lapangan (Kleim, 2018).

\section{Bersama Kehendak Langit}

Wirausaha harus seperti Ilmu Nahwu dalam Bahasa Arab yaitu harus bisa Marfu' (dhummah) dan Manshub (fathah), jangan seperti Majrur dan Majzum. Marfu' yang berarti memeluk atau merangkul, sedangkan Manshub yang berarti terbuka tanpa ada yang ditutupi. Jangan seperti Majrur yang berarti menginjak-injak atau merendahkan orang lain. (Maula, Mufidah, Rosyidah, \& Purnomo, 2017; Qori'ah, Sholichah, Purnomo, \& Rosyidah, 2017). Setiap manusia yang memiliki ilmu termasuk ilmu wirausaha selayaknya harus mengamalkan ilmu tersebut (Asitah, Usmawati, Rosyidah, \& Purnomo, 2017). Tips mengelola institusi wirausaha adalah niat mendidik dan berjuang karena Allah ta'ala. Niscaya rintangan sebesar apapun akan terasa ringan dihadapan kita 
(Yuniarti, Kautsari, Sholichah, Purnomo, \& Rosyidah, 2017). Wirausaha senantiasa harus selalu berpegang teguh pada sifat yang dimiliki oleh Rasul (Munjidah, Zannah, Purnomo, \& Rosyidah, 2017).

\section{Melayani Bisa Menjadi Berkah}

Kita semua bermimpi membangun platform SaaS yang menarik jutaan pengguna dan menghasilkan uang saat kita tidur. Tetapi untuk sampai ke sana, Anda biasanya butuh uang. Banyak uang. Bergantung pada vertikal yang Anda tangani: servis bisa menjadi langkah pertama yang baik yang akan membantu Anda memulai, menyalakan lampu, dan menghasilkan pendapatan sambil belajar dari pelanggan pertama Anda. Anda kemudian dapat bootstrap jalan Anda ke pasaran produk-pasar di mana Anda akan berada dalam posisi yang jauh lebih menguntungkan untuk mengumpulkan modal (Anda sudah memiliki pelanggan!) Dan membangun SaaS pemenang berdasarkan pembelajaran Anda (Mérineau, 2017).

\section{Kelola Pengeluaran Anda}

Karena ini adalah bisnis baru, Anda mungkin bertekad untuk membuatnya bekerja dan akhirnya menghabiskan banyak uang untuk pengeluaran yang tidak perlu. Buatlah daftar hal-hal terpenting yang akan membantu meningkatkan bisnis dan 
menyiapkan uang tunai untuk dibeli. Memiliki anggaran yang masuk akal sehingga Anda tetap ramping dan fokus (Kleim, 2018).

\section{Jangan Mencoba Menggunakan Setiap Saluran Pemasaran dan Fokus pada Apa Yang Berhasil untuk Anda}

Mulailah dengan 1 atau 2 saluran komunikasi dan penerbitan utama tempat Anda dapat mengirim orang. Lakukan percobaan dengan titik sentuh lain yang Anda tahu orang lain gunakan. Mereka mungkin melakukan Facebook Lives, Instagram Stories, Snapchat, dan layering pada cara lain untuk menjangkau audiens baru seperti iklan Facebook, wawancara tamu, dan kemitraan strategis. Tetap sederhana dan selalu mengirim orang kembali ke saluran utama (Basu, 2018).

\section{Tahu Kapan Harus Berhenti}

Pengusaha yang bijak tahu kapan harus terjun ke bisnis dan kapan berhenti. Jangan biarkan ego Anda menjatuhkan Anda. Jika ide Anda tidak terwujud, fokuskan pada apa yang salah dan pelajari dari kesalahan yang terjadi. Jika Anda terus kehilangan uang pada detik, dan Anda telah kehabisan semua keterampilan bertahan hidup, sekarang saatnya untuk berhenti. Ini penting bagi Anda karena Anda dapat belajar dari kesalahan dan 
melanjutkan. Berhenti dan jelajahilah sesuatu yang lain (Kleim, 2018).

\section{Memiliki Rencana Bisnis yang Solid}

Perencanaan memainkan peran penting dalam kesuksesan bisnis. Rencana bisnis adalah tempat yang baik untuk memulai - mendefinisikan keterampilan dan kelemahan Anda, apa yang Anda tawarkan, bagaimana itu unik dan bagaimana Anda berencana mengembangkan penawaran Anda. Terlebih lagi, coba persiapkan diri Anda secara mental dan praktis untuk apa pun yang bisa salah dan bagaimana Anda akan menghadapinya. Misalnya, apa yang terjadi jika Anda terluka? Bagaimana jika klien membayar Anda terlambat satu bulan? Bagaimana jika bencana cuaca mempengaruhi Anda? Atau pemasok tepercaya bangkrut? (Santam, 2018).

\section{Identifikasi Peluang}

Setiap wirausahawan yang sukses mendapatkan kesempatan mereka karena mereka mengidentifikasi peluang yang tidak diperhatikan atau dimanfaatkan oleh orang lain. Akan bermanfaat jika Anda terbiasa mengidentifikasi peluang di usia muda itu sendiri (Emerson, 2017). 


\section{Tidak Ada Glam, Hanya Keringat}

Bijaksana dan pantang menyerah dalam belajar dan berwirausaha adalah kunci kesuksesan hidup dan wirausaha (Nahdiyah, Amrina, Purnomo, \& Rosyidah, 2017). Meluncurkan startup pasti terdengar keren. Ketika Anda melihat dua puluh sesuatu seperti Evan Spiegel membuat sampul majalah Forbes, Anda tidak dapat membantu tetapi memimpikan lintasan yang sama untuk diri sendiri. Kami mendapat berita untuk Anda: kewirausahaan tidak se-glamor seperti kelihatannya. Pada akhirnya, "CEO of nothing" adalah gelar yang dimuliakan untuk "pengangguran". Kepada semua wirausahawan yang memiliki cita-cita, kami katakan ini: jika Anda pikir Anda akan mendapatkan banyak uang dan memiliki pasukan orang yang melakukan kerja keras untuk Anda saat Anda berbicara di konferensi dan menjalani gaya hidup mewah, Anda terlalu banyak melamun. Jika Anda belum siap untuk menyingsingkan lengan baju dan berdarah di parit selama tahun pertama, Anda sudah mati di dalam air (Mérineau, 2017). 


\section{Berkomitmen Sebelum Berangkat tanpa Terhubung}

Memahami bahwa hasilnya mungkin tidak dapat dikontrol, tetapi inputnya. Jadi fokuskan 100 persen pada input, bebas dari melampirkan harga diri Anda pada hasilnya (Meis, 2017).

\section{Membagikan Kisah Pribadi Anda dapat Membantu Menciptakan Koneksi yang Lebih Kuat dengan Orang Lain}

Kita sering berpikir bahwa kita akan dihakimi atau diejek karena rentan dan terbuka, tetapi apa yang terjadi secara dramatis berbeda. Ketika kita terbuka dan berbagi bagian dari diri kita, kita menjadi lebih manusiawi, dan kemanusiaan itulah yang menghubungkan kita satu sama lain. Jadi, jika Anda ingin mengembangkan koneksi dengan suku, keterlibatan dengan suku, orang-orang yang benar-benar memahami Anda dan pesan Anda, Anda perlu membuka dan berbagi cerita Anda (Basu, 2018).

\section{Ambil Tindakan Terus-Menerus}

Senantiasa belajar dan bekerja keras. Bersabarlah dengan masalah, sesungguhnya didalam kesulitan ada kemudahan (Sholichah, Istiqomah, Rosyidah, \& Purnomo, 2017). Pengusaha membuat sesuatu terjadi. Mereka tidak bisa hanya 
duduk dan menganalisis setiap detail. Jika mereka tidak, mereka tidak akan pernah ke mana pun. Pada awalnya, tidak ada ruang untuk menunda-nunda. Ini adalah pekerjaan 24/7 tanpa hari sakit atau liburan yang membutuhkan momentum maju secara berkelanjutan. Di setiap langkah di sepanjang jalan, nilai sebentar dan kemudian bergerak maju (Reynolds, 2016).

\section{Jangan Berhenti Belajar}

Edupreneur atau educational entrepreneur berasal dari dua kata yaitu education bermakna pendidikan dan entrepreneur bermakna pengusaha atau wirausahawan. Ada juga yang menyamakan istilah edupreneur dengan istilah teacherpreneur (Purnomo, 2017). Pendidikan wirausaha bertujuan menyampaikan ilmu dan mentransformasi orang lain menjadi pengusaha yang lebih baik (Fidiana, Istiana, Rosyidah, \& Purnomo, 2017). Pengusaha paling sukses adalah mereka yang tidak pernah berhenti membaca dan belajar. Mereka tidak pernah menganggap diri mereka sebagai orang terpintar di ruangan itu dan terus-menerus mencari cara untuk mempelajari hal-hal baru dan mengelilingi diri mereka dengan orang-orang yang lebih pintar. Semakin Anda membuka pikiran untuk mempelajari hal-hal baru, semakin banyak keterampilan yang akan Anda kembangkan dan itu akan membantu 
Anda mengembangkan keterampilan wirausaha utama seperti menjadi pemimpin, visioner, dan salesman (Emerson, 2017).

\section{References}

Asitah, N., Usmawati, D. Z., Rosyidah, E., \&

Purnomo, A. (2017). MI Hasyim Asy'ari Ilmu

Harus Terus Mengarus. In Wirausaha

Pendidikan Indonesia (Jilid 2). Sidoarjo:

UNUSIDA Press.

Basu, T. (2018). Top 20 Tips for Building a Business from Successful Entrepreneurs.

Retrieved May 14, 2019, from

https://www.thinkific.com/blog/tips-buildinga-business-successful-entrepreneurs/

Emerson, M. (2017). 8 Habits to Become a Successful Young Entrepreneur. Retrieved May 14, 2019, from https://succeedasyourownboss.com/8-habitsbecome-successful-young-entrepreneur/

Fidiana, W., Istiana, Z., Rosyidah, E., \& Purnomo,

A. (2017). MINU Waru 2 Insan Berkilau Cahaya Manfaat. In Wirausaha Pendidikan Indonesia (Jilid 4). Sidoarjo: UNUSIDA Press.

Kleim, M. (2018). Top 10 Tips For First-Time Entrepreneurs Willing To Be Successful. Retrieved May 26, 2019, from https://smallbizsense.com/10-tips-for-first-timeentrepreneurs/ 
L'Écuyer, J.-P. (2016). Ten Tips to Becoming a Better Entrepreneur. Retrieved May 14, 2019, from

https://www.futurpreneur.ca/en/2016/ten-tipsto-becoming-a-better-entrepreneur/

Maula, I., Mufidah, F. I., Rosyidah, E., \& Purnomo, A. (2017). SD Antawirya Islamic Javanese School Mother is Culture. In Wirausaha Pendidikan Indonesia (Jilid 1). Sidoarjo: UNUSIDA Press.

Meis, C. (2017). 7 Tips for the Struggling Entrepreneur. Retrieved June 14, 2019, from https://www.success.com/7-tips-for-thestruggling-entrepreneur/

Mérineau, É. (2017). 17 tips for first-time entrepreneurs in 2017. Retrieved May 14, 2019, from

https://medium.com/@etiennemerineau/17tips-for-first-time-entrepreneurs-in-2017e98cda59aa41

Munjidah, A., Zannah, I. P. N., Purnomo, A., \& Rosyidah, E. (2017). MI Thoriqussalam Berpegang Kepada Rosul. In Wirausaha Pendidikan Indonesia (Jilid 4). Sidoarjo: UNUSIDA Press.

Nahdiyah, K., Amrina, S., Purnomo, A., \& Rosyidah, E. (2017). SD Taman Pendidikan Islam Porong Iman Kuat Bekal di Akhirat. In Wirausaha Pendidikan Indonesia (Jilid 2). Sidoarjo: UNUSIDA Press. 
Purnomo, A. (2017). Pengertian Edupreneur. https://doi.org/10.31227/osf.io/8fnu6

Qori'ah, S., Sholichah, S. A., Purnomo, A., \&

Rosyidah, E. (2017). Progresif Bumi Sholawat dengan Kebenaran Semua Pasti Ada Jalan. In Wirausaha Pendidikan Indonesia (Jilid 3). Sidoarjo: UNUSIDA Press.

Reynolds, C. (2016). 8 Tips For Becoming a Successful Entrepreneur. Retrieved June 14, 2019, from

https://www.business2community.com/strateg y/8-tips-becoming-successful-entrepreneur01567069

Santam. (2018). 10 tips for becoming a successful entrepreneur. Retrieved June 14, 2019, from https://www.santam.co.za/blog/businessadvice/10-tips-for-becoming-a-successfulentrepreneur/

Setyawati, I., Purnomo, A., Irawan, D. E., Tamyiz, M., \& Sutiksno, D. U. (2018). A Visual Trend of Literature on Ecopreneurship Research Overviewed within The Last two Decades. Journal of Entrepreneurship Education, 21(4), $1-7$. Retrieved from https://www.abacademies.org/articles/avisual-trend-of-literature-on-ecopreneurshipresearch-overviewed-within-the-last-twodecades-7468.html

Sholichah, S. A., Istiqomah, A., Rosyidah, E., \& Purnomo, A. (2017). MI Darun Najah Berfikir Berkarya Berdzikir. In Wirausaha Pendidikan Indonesia (Jilid 3). Sidoarjo: UNUSIDA 
Press.

Yuniarti, D., Kautsari, M. F., Sholichah, F.,

Purnomo, A., \& Rosyidah, E. (2017). SMP

SMA Al-Amin Ponpes Bahrul Hidayah

Serahkan pada Allah Ta'ala. In Wirausaha

Pendidikan Indonesia (Jilid 1). Sidoarjo:

UNUSIDA Press. 